\title{
1,7-Bis(4-hydroxy-3-methoxyphenyl)-1,4,6-heptatrien-3-one alleviates lipopolysaccharide-induced inflammation by targeting NF-кB translocation in murine macrophages and it interacts with MD2 in silico
}

\author{
CHUTIMA JANSAKUN ${ }^{1,2}$, WANATSANAN CHULRIK ${ }^{1,2}$, WARALUCK CHAICHOMPOO ${ }^{3}$, \\ PATHUMWADEE YOTMANEE ${ }^{3}$, KANOKPORN LEHBOON $^{3}$, WILANEE CHUNGLOK ${ }^{4}$, \\ APSORN SATTAYAKHOM ${ }^{1,2}$, POONSIT HIRANSAI ${ }^{1,2}$, KORNYOK KAMDEE $^{1,2}$, \\ TANYARATH UTAIPAN $^{5}$, APICHART SUKSAMRARN ${ }^{3}$ and WARANGKANA CHUNGLOK ${ }^{1,2}$
}

\author{
${ }^{1}$ School of Allied Health Sciences and ${ }^{2}$ Research Institute for Health Sciences, Walailak University, Nakhon Si \\ Thammarat 80161; ${ }^{3}$ Department of Chemistry and Center of Excellence for Innovation in Chemistry, Faculty of Science, \\ Ramkhamhaeng University, Bangkok 10240; ${ }^{4}$ Department of Microbiology, Faculty of Science, Prince of Songkla University, \\ Songkhla 90110; ${ }^{5}$ Department of Pre-Clinic, Faculty of Science and Technology, \\ Prince of Songkla University, Pattani Campus, Pattani 94000, Thailand
}

Received May 22, 2020; Accepted November 10, 2020

DOI: $10.3892 / \mathrm{mmr} .2021 .11848$

\begin{abstract}
Trienones are curcuminoid analogues and are minor constituents in the rhizomes of numerous Curcuma plant species. Studies investigating the biological activities of trienones, particularly their anti-inflammatory activities, are limited. In the present study, the trienone 1,7-bis(4-hydroxy-3methoxyphenyl)-1,4,6-heptatrien-3-one (HMPH) was structurally modified from curcumin using a novel and concise method. HMPH was shown to exhibit potential anti-inflammatory effects on lipopolysaccharide (LPS)-activated RAW264.7 macrophages. Furthermore, LPS-induced nitric oxide secretion in RAW264.7 cells was markedly and dose-dependently inhibited by HMPH; in addition, HMPH had a greater efficacy compared with curcumin. This inhibition was accompanied by the suppression of inducible nitric oxide synthase and cyclooxygenase-2 expression, as well as pro-inflammatory cytokine secretion. To elucidate the molecular mechanism underlying the anti-inflammatory effects of HMPH, the effects of this compound on nuclear factor- $\kappa \mathrm{B}(\mathrm{NF}-\kappa \mathrm{B})$ translocation were assessed. HMPH significantly inhibited the translocation of
\end{abstract}

Correspondence to: Dr Warangkana Chunglok, School of Allied Health Sciences, Walailak University, 222 Thaiburi, Thasala, Nakhon Si Thammarat 80161, Thailand

E-mail: aon.cwarang@gmail.com; cwarang@wu.ac.th

Abbreviations: COX, cyclooxygenase; iNOS, inducible nitric oxide synthase; LPS, lipopolysaccharide; MD2, myeloid differentiation factor $2 ; \mathrm{NF}-\kappa \mathrm{B}$, nuclear factor- $\kappa \mathrm{B}$; NO, nitric oxide; TLR4, Toll-like receptor 4

Key words: trienone, curcumin, $\mathrm{NF}-\kappa \mathrm{B}, \mathrm{MD} 2$ p65 NF- $\kappa \mathrm{B}$ into the nucleus to a greater extent than curcumin, thus indicating that HMPH has more potent anti-inflammatory activity than curcumin. In addition, an in silico modelling study revealed that HMPH possessed stronger binding energy to myeloid differentiation factor 2 (MD2) compared with that of curcumin, and indicated that the anti-inflammatory effects of HMPH may be through upstream inhibition of the inflammatory pathway. In conclusion, HMPH may be considered a promising compound for reducing inflammation via targeting p65 NF- $\mathrm{KB}$ translocation and interfering with MD2 binding.

\section{Introduction}

Macrophages have been reported to have a significant role in contributing to poor clinical outcomes in sepsis and infections caused by gram-negative bacteria $(1,2)$. During infection, lipopolysaccharide (LPS), an important component of gram-negative bacteria, binds to the Toll-like receptor 4 (TLR4)/myeloid differentiation factor 2 (MD2) complex in macrophages, which leads to the induction of immune exacerbation (3). An uncontrolled macrophage inflammatory response can cause tissue damage, systemic inflammation and various chronic inflammatory diseases (4). The potentiation of TLR4/MD2 by LPS drives activation of nuclear factor- $\kappa \mathrm{B}(\mathrm{NF}-\kappa \mathrm{B})$ and constitutive inflammatory signalling by binding to the promoter of inflammatory genes (5). Activation of NF- $\mathrm{KB}$ occurs through the inducible degradation of its inhibitor, I $\kappa \mathrm{B} \alpha$, which is triggered through the phosphorylation of IKK complexes, thereby causing the ubiquitination

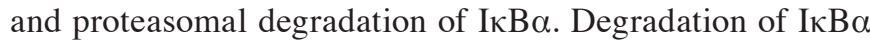
results in a rapid and transient nuclear translocation of the $\mathrm{NF}-\kappa \mathrm{B}$ transcription factor (6). Numerous NF- $\kappa \mathrm{B}$ target genes are involved in the inflammatory response, including inducible nitric oxide synthase (iNOS), cyclooxygenase (COX)-2 and 
inflammatory cytokines $(7,8)$. Inhibition of the LPS-stimulated formation of the TLR4/MD2 complex and NF- $\kappa$ B activation in macrophages has been proposed as a target of intervention for acute and chronic inflammatory diseases $(9,10)$.

Several natural compounds derived from the Curcuma species have been revealed to be promising compounds for the development of novel drugs. Among them, turmeric (Curcuma longa L.) is a species of plant belonging to the Zingiberaceae family and has been investigated as a rich source of bioactive compounds (11). Curcuminoids are multifunctional polyphenolic compounds found in the rhizome of turmeric (12). The natural trienone analogue of curcumin,1,7-bis(4-hydroxy-3-me thoxyphenyl)-1,4,6-heptatrien-3-one (HMPH), has previously been isolated as a minor component from $C$. longa (13). Few studies have investigated the biological activities of trienones. Trienones have previously been shown to possess cytotoxicity against KB oral cancer cells (14), PC-3 prostate cancer cells (15) and oral squamous cell carcinoma cells (16), as well as inhibitory effects on steroid 5- $\alpha$ reductase activity (17) and TNF- $\alpha$ production (18). To the best of our knowledge, the anti-inflammatory activity of trienones in LPS-activated RAW264.7 macrophages has not yet been precisely elucidated by comparing the results with curcumin. The anti-inflammatory activity of curcumin has been reported to be associated with the suppression of iNOS (19) and COX-2 (20) in LPS-activated RAW264.7 cells by targeting various transcription factors, including $\mathrm{NF}-\kappa \mathrm{B}$ signalling proteins. In addition, curcumin has been shown to interfere with the binding of LPS to the TLR4/MD2 complex, consequently suppressing activation of the inflammatory pathway (21). However, the drawbacks of curcumin are its low oral bioavailability, instability at physiological $\mathrm{pH}$, low solubility in water and rapid metabolism $(22,23)$. This has prompted researchers to search for novel curcuminoid analogues with powerful therapeutic potential to use as anti-inflammatory agents for the treatment of various inflammatory diseases, or to use this class of compounds as the backbone for designing new drugs.

The present study aimed to investigate the anti-inflammatory effect of $\mathrm{HMPH}$, which is structurally related to curcumin from $C$. longa in LPS-activated macrophages. In order to ensure a sufficient supply of HMPH, a novel method of synthesis of this compound from curcumin was developed. Subsequently, the anti-inflammatory role of HMPH on iNOS/nitric oxide (NO), COX-2 and pro-inflammatory cytokine production was investigated. Furthermore, to clarify the mechanism of action of $\mathrm{HMPH}$, the critical regulatory protein p65 NF- $\mathrm{B}$ and the interaction of HMPH with MD2 were additionally evaluated using an in silico modelling study.

\section{Materials and methods}

Synthesis of $H M P H$. Curcumin was obtained from $C$. longa as described previously (24). Curcumin (1.2 g, $3.24 \mathrm{mmol})$ was dissolved in tetrahydrofuran (THF; $30 \mathrm{ml})$ and $\mathrm{NaBH}_{4}(50 \mathrm{mg}$, $1.32 \mathrm{mmol}$ ) was added. The reaction mixture was stirred at room temperature for $4 \mathrm{~h}$. Water $(200 \mathrm{ml})$ was then added and the mixture was extracted with EtOAc. The organic phase was washed with water, dried over anhydrous $\mathrm{Na}_{2} \mathrm{SO}_{4}$ and the solvent was evaporated until dry. The obtained crude product was dissolved in THF $(30 \mathrm{ml})$ and p-toluenesulfonic acid monohydrate $(50 \mathrm{mg})$ was then added. The reaction mixture was refluxed for $3 \mathrm{~h}$, water was added and the mixture was extracted with EtOAc (2x100 ml). The combined organic phase was washed with water and dried over anhydrous $\mathrm{Na}_{2} \mathrm{SO}_{4}$; the solvent was evaporated and the residue was chromatographed on a silica column (particle size, $<0.063 \mathrm{~mm}$; silica gel 60 ; EMD Millipore) using hexane-EtOAc (3:2) and further purified on a Sephadex LH-20 column eluted with $\mathrm{MeOH}$ to yield HMPH (Fig. 1A). A total of $240 \mathrm{mg}$ (21\% overall yield from curcumin) of HMPH was obtained (Fig. S1). The ${ }^{1} \mathrm{H}$ and ${ }^{13}$ C NMR (Figs. S2 and S3) and mass spectral data (data not shown) were consistent with the reported values (24).

Cell line and culture. The mouse macrophage cell line, RAW264.7 was purchased from American Type Culture Collection. Cells were cultured in RPMI-1640 medium (Corning, Inc.) supplemented with $10 \%$ foetal bovine serum (Biochrom, Ltd.), $1 \%$ penicillin/streptomycin and $2 \mathrm{mM}$ stable L-glutamine (Gibco; Thermo Fisher Scientific, Inc.) in an atmosphere containing $95 \%$ humidity and $5 \% \mathrm{CO}_{2}$ at $37^{\circ} \mathrm{C}$. In all experiments, the cell line was cultured for $24 \mathrm{~h}$ and cell passages 21-30 were used for experimentation.

Measurement of cytotoxicity. To measure cell viability of HMPH, the MTT assay (Sigma-Aldrich; Merck KGaA) was performed. RAW264.7 cells were plated into 96-well plates at a density of $3 \times 10^{5}$ cells $/ \mathrm{cm}^{2}$. After $24 \mathrm{~h}$, cells were pretreated with HMPH or curcumin at different concentrations $(0.63-20 \mu \mathrm{M})$ for $1 \mathrm{~h}$ at $37^{\circ} \mathrm{C}$, then incubated with LPS (10 ng/ml) (Escherichia coli 0111:B4; Sigma-Aldrich; Merck KGaA) for $24 \mathrm{~h}$. After a $3 \mathrm{~h}$ incubation period with MTT $(0.5 \mathrm{mg} / \mathrm{ml})$ solution, the formazan crystals were dissolved in DMSO and absorbance was measured at $560 \mathrm{~nm}$.

Measurement of NO production. RAW264.7 cells $\left(3.0 \times 10^{5}\right.$ cells $\left./ \mathrm{cm}^{2}\right)$ were cultured in 96 -well plates. To avoid the direct interaction of the test compounds with LPS and the presence of a high inflammatory background, cells were pretreated with the test compounds for $1 \mathrm{~h}$ prior to LPS stimulation. Briefly, cells were incubated with HMPH or curcumin $(0.63-20 \mu \mathrm{M})$, an inhibitor of $\mathrm{I} \kappa \mathrm{B} \alpha$ phosphorylation (BAY 11-7082; $10 \mu \mathrm{M}$; Sigma-Aldrich; Merck KGaA) and an anti-inflammatory drug (dexamethasone; $10 \mu \mathrm{M}$; Sigma-Aldrich; Merck KGaA) for $1 \mathrm{~h}$ prior to LPS (10 ng/ml) stimulation for $24 \mathrm{~h}$. Nitrite concentration in the cultured medium was measured using Griess reagent (Sigma-Aldrich; Merck KGaA) (25). The optical density was measured at $540 \mathrm{~nm}$.

Measurement of inflammatory cytokines. RAW264.7 cells were plated at a density of $3.0 \times 10^{5}$ cells $/ \mathrm{cm}^{2}$ in 96 -well plates for $24 \mathrm{~h}$. Cells were treated with HMPH and curcumin at different concentrations $(5-20 \mu \mathrm{M})$ and BAY 11-7082 $(10 \mu \mathrm{M})$ for $1 \mathrm{~h}$ followed by LPS (10 ng/ml) stimulation for $24 \mathrm{~h}$. Subsequently, culture medium was analysed using ELISA kits for TNF- $\alpha$ (cat. no. 430904), IL-6 (cat. no. 431304) and IL-1 $\beta$ (cat. no. 432604), according to the manufacturer's protocols (BioLegend, Inc.).

Preparation of nuclear and cytosolic extracts. RAW264.7 cells were pretreated with HMPH and curcumin $(5-20 \mu \mathrm{M})$ and BAY 11-7082 $(10 \mu \mathrm{M})$ for $1 \mathrm{~h}$ followed by LPS (10 $\mathrm{ng} / \mathrm{ml})$ stimulation for $15 \mathrm{~min}$. Nuclear and cytoplasmic extracts were prepared 
A<smiles>COc1cc(/C=C/C=C/C(=O)/C=C/c2ccc(O)c(OC)c2)ccc1O</smiles>

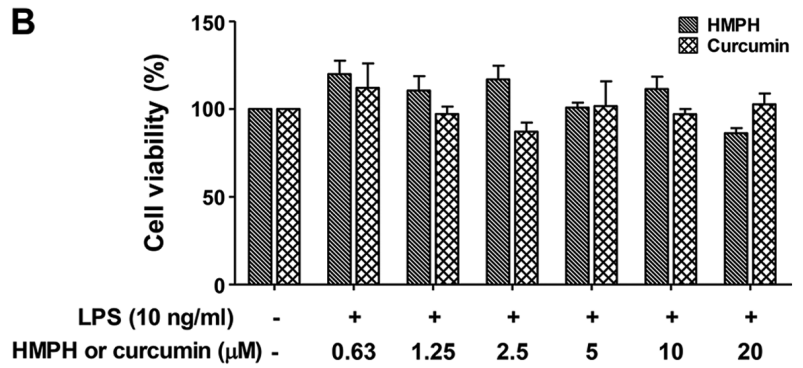

Figure 1. Chemical structure and cytotoxicity of HMPH. (A) Structure of HMPH. (B) Cytotoxic effect of HMPH. RAW264.7 macrophages were pretreated with HMPH and curcumin at indicated concentrations $(0.63-20 \mu \mathrm{M})$ for $1 \mathrm{~h}$ followed by LPS $(10 \mathrm{ng} / \mathrm{ml})$ treatment for $24 \mathrm{~h}$. Cell viability was investigated using MTT assay. Data are presented as the mean \pm SEM of three independent experiments performed in triplicate. HMPH, 1,7-bis(4-hydroxy-3methoxyphenyl)-1,4,6-heptatrien-3-one; LPS, lipopolysaccharide.

using NE-PER ${ }^{\mathrm{TM}}$ Nuclear and Cytoplasmic Extraction Reagents (cat. no. 78835; Thermo Fisher Scientific, Inc.) according to the manufacturer's guidelines. The nuclear and cytoplasmic proteins were then assessed by western blot analysis.

Western blot analysis. RAW264.7 cells were cultured at a concentration of $3.0 \times 10^{5}$ cells $/ \mathrm{cm}^{2}$ on 6 -well plates. Cells were pretreated with HMPH and curcumin (5-20 $\mu \mathrm{M})$, BAY 11-7082 $(10 \mu \mathrm{M})$ and dexamethasone $(10 \mu \mathrm{M})$ for $1 \mathrm{~h}$, then cells were activated with LPS (10 ng/ml) for $15 \mathrm{~min}$ for $\mathrm{p} 65 \mathrm{NF}-\kappa \mathrm{B}$ detection or $24 \mathrm{~h}$ for iNOS and COX-2 detection. Cells were washed three times with ice-cold PBS and lysed with lysis buffer containing protease inhibitors (Cell Signaling Technology, Inc.). Cell lysates were centrifuged at $12,000 \mathrm{x} \mathrm{g}$ for $15 \mathrm{~min}$ at $4^{\circ} \mathrm{C}$. The supernatant was collected and protein concentrations were determined using the detergent compatible protein assay kit (BioRad Laboratories, Inc.). Briefly, 30-50 $\mu \mathrm{g}$ protein was loaded, separated by SDS-PAGE on 7.5 and $10 \%$ gels, and then transferred to polyvinylidene fluoride membranes. The membranes were blocked with $5 \%$ non-fat dry milk in Tris-buffered saline and $0.1 \%$ Tween-20 (TBST) for $1 \mathrm{~h}$ at room temperature, and incubated with primary antibodies against iNOS (1:1,000; cat. no. 13120), COX-2 (1:1,000; cat. no. 4842), p65 NF- $\mathrm{B}(1: 1,000$; cat. no. 8242), $\beta$-actin $(1: 5,000$; cat. no. 4967) and lamin B1 (1:1,000; cat. no. 13435) (Cell Signaling Technology, Inc.) at $4^{\circ} \mathrm{C}$ overnight. Each membrane was then washed with TBST followed by incubation with anti-rabbit HRP-conjugated secondary antibody (1:2,000; cat. no. 7074; Cell Signaling Technology, Inc.) at room temperature for $1 \mathrm{~h}$ under agitation. Blots were visualized using the chemiluminescent HRP detection reagent (EMD Millipore). GeneSys software version 1.2.5.0 (Synoptics, Ltd.) was used to acquire iNOS, COX-2 (HMPH treatment group) and associated $\beta$-actin images, and Image $\mathrm{Lab}^{\mathrm{TM}}$ Touch Software (Bio-Rad Laboratories, Inc.) was used to acquire the images of p65 NF- $\mathrm{B}$, lamin B1, COX-2 (curcumin treatment group) and associated $\beta$-actin. Signal intensities were densitometrically semi-quantified using ImageJ V1.8.0 software program (National Institute of Health).
Immunofluorescence staining. RAW264.7 cells $\left(3.0 \times 10^{5}\right.$ cells $/ \mathrm{cm}^{2}$ ) were seeded on coverslips on 24-well plates for $24 \mathrm{~h}$. Cells were pretreated with HMPH $(20 \mu \mathrm{M})$, curcumin $(20 \mu \mathrm{M})$ or BAY 11-7082 $(10 \mu \mathrm{M})$ for $1 \mathrm{~h}$, and were then treated with LPS $(10 \mathrm{ng} / \mathrm{ml})$ for 15 or $30 \mathrm{~min}$. Cells were washed three times with ice-cold PBS, fixed in pre-cooled methanol $\left(-20^{\circ} \mathrm{C}\right)$ for $5 \mathrm{~min}$ and immersed in cold acetone. The fixed cells were blocked in $1 \%$ bovine serum albumin (Sigma-Aldrich; Merck KGaA) in PBS containing $0.1 \%$ Tween-20 (PBST) for $30 \mathrm{~min}$ and then incubated with anti-p65 NF-кB antibody (1:200; cat. no. 8242; Cell Signalling Technology, Inc.) at room temperature for $1 \mathrm{~h}$. After washing in PBST, the cells were incubated with anti-rabbit secondary antibody conjugated with Alexa Fluor-488 (1:400; cat. no. 4412S; Cell Signaling Technology, Inc.) alongside propidium iodide $(2.5 \mu \mathrm{g} / \mathrm{ml})$ at room temperature for $1 \mathrm{~h}$. The coverslips were mounted on microscope slides and images were captured using a Leica TCS SP5 II laser scanning confocal microscope (Leica Microsystems GmbH).

Pretreatment with compounds before LPS stimulation. RAW264.7 cells $\left(3.0 \times 10^{5}\right.$ cells $\left./ \mathrm{cm}^{2}\right)$ were seeded on 6-well plates and incubated at $37^{\circ} \mathrm{C}$ for $24 \mathrm{~h}$ in an incubator containing $5 \% \mathrm{CO}_{2}$. Cells were incubated in the presence or absence of various concentrations of HMPH and curcumin $(5-20 \mu \mathrm{M})$ and BAY 11-7082 $(10 \mu \mathrm{M})$ for $1 \mathrm{~h}$, and were washed three times with serum-free medium before incubation with LPS $(10 \mathrm{ng} / \mathrm{ml})$ for $24 \mathrm{~h}$. The culture supernatant was collected and the nitrite accumulated in the supernatant was determined by the Griess assay.

Molecular docking analysis. The crystal structure of human MD2-lipid IVa complex (PDB code 2E59) was used as the initial coordinates for the molecular docking calculations using AutoDock4.2 (26). The docking input files and analysed docking results were generated from AutoDockTools1.5.6 (26). A grid box dimension of $60 \times 60 \times 60 \AA^{3}$ with a spacing of $0.375 \AA$ between the grid points was created and centred on the ligand. The Lamarckian genetic algorithm was employed for the docking calculations to enable modification of the gene population (27). The docking parameters were as follows: A total of 250 independent runs, a population size of 150 , and a maximum of 25,000,000 energy evaluations. MD2 protein was set rigid but all torsional bonds of the ligand were freely rotated. Non-polar hydrogens of the molecule were merged and each atom was assigned with Gasteiger partial charges. The lowest docked energy of each conformation in the most populated cluster was selected for the detailed analysis and further study. Visualisation of the docking results was performed using Biovia Discovery Studio Visualizer (Dassault Systèmes).

Molecular Mechanics/Poisson Boltzmann Surface Area (MM/PBSA) free energy analysis. The energy minimisations of the docked MD2-HMPH and MD2-curcumin complexes were performed using the SANDER module of AMBER16 packages (28). To remove bad contacts, the systems were minimised starting with the steepest descent followed by the conjugate gradient. The minimized complexes were solvated by water molecules. Then, the systems were heated progressively from 0 to $300 \mathrm{~K}$ for $100 \mathrm{ps}$ and equilibrated at $300 \mathrm{~K}$ for $200 \mathrm{ps}$ in the canonical (NVT) and isothermal-isobaric (NPT) ensembles, respectively. The last snapshot obtained from the equilibrated 


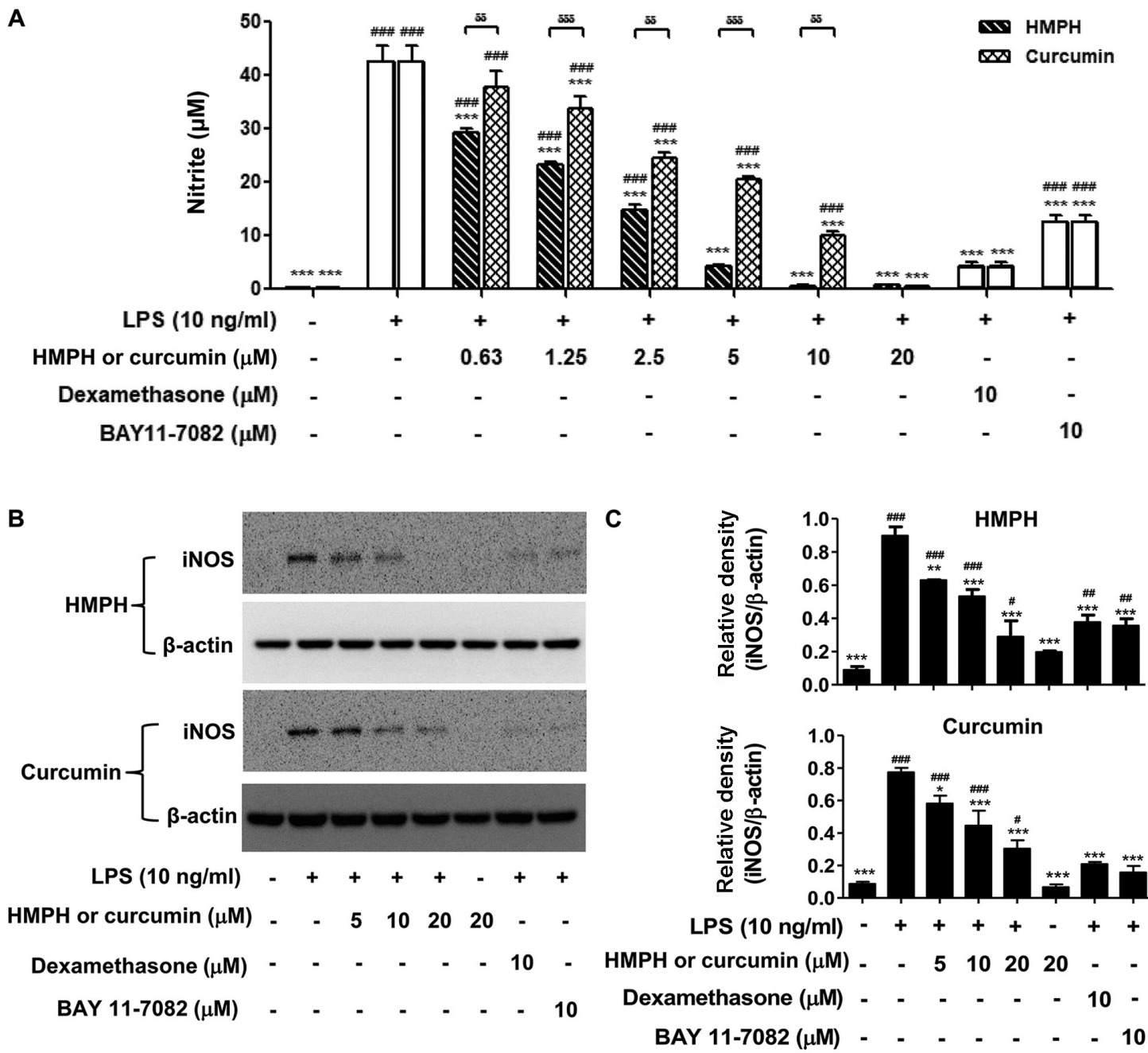

Figure 2. HMPH suppresses NO production and iNOS protein expression levels in LPS-activated RAW264.7 macrophages. (A) NO production upon stimulation with LPS $(10 \mathrm{ng} / \mathrm{ml})$ with or without HMPH and curcumin $(0.63-20 \mu \mathrm{M})$ was detected by Griess assay. Cell lysates were prepared from RAW264.7 cells pretreated with or without HMPH and curcumin for $1 \mathrm{~h}$ followed by LPS treatment for $24 \mathrm{~h}$. (B) Protein expression levels of iNOS were determined by western blotting. The representative images of iNOS and $\beta$-actin were from two different parts of the same blotted membranes, with an exposure time of 15 min for iNOS and 10-25 sec for $\beta$-actin. (C) Relative expression levels of iNOS were semi-quantified by scanning densitometry and normalized to $\beta$-actin. Data are presented as the mean \pm SEM of three independent experiments. ${ }^{~} \mathrm{P}<0.05,{ }^{\# \#} \mathrm{P}<0.01,{ }^{\# \# \#} \mathrm{P}<0.001$ vs. control group; ${ }^{*} \mathrm{P}<0.05,{ }^{* *} \mathrm{P}<0.01,{ }^{* * *} \mathrm{P}<0.00$ vs. LPS-stimulated group; ${ }^{\delta \delta} \mathrm{P}<0.01,{ }^{\delta \delta \delta} \mathrm{P}<0.001$ vs. curcumin-treated group. $\mathrm{HMPH}, 1,7$-bis(4-hydroxy-3-methoxyphenyl)-1,4,6-heptatrien-3-one; LPS, lipopolysaccharide; NO, nitric oxide; iNOS, inducible nitric oxide synthase.

phase was used as the suitable structure of the complex for calculating the binding free energy value using the MM/PBSA module $\left(\Delta \mathrm{G}_{\mathrm{MM} / \mathrm{PBSA}}\right)$ in the AMBER 16 programme; this methodology provides more reliable binding energy values.

Statistical analysis. Data are presented as the mean \pm SEM of three independent experiments. Statistical significance was evaluated by one-way or two-way ANOVA followed by Bonferroni multiple comparison test. $\mathrm{P}<0.05$ was considered to indicate a statistically significant difference. The statistical analyses were performed using GraphPad Prism 6 (GraphPad Software, Inc.).

\section{Results}

Effect of HMPH on cell viability. The present study investigated the effect of HMPH on the cell viability of RAW264.7 macrophages. Cells were treated with the test compounds in increasing concentrations between 0.63 and $20 \mu \mathrm{M}$, followed by treatment with LPS $(10 \mathrm{ng} / \mathrm{ml})$ for $24 \mathrm{~h}$. HMPH did not affect the viability of RAW264.7 cells at concentrations up to $20 \mu \mathrm{M}$ in combination with $10 \mathrm{ng} / \mathrm{ml} \mathrm{LPS}$; similar results were observed for curcumin (Fig. 1B).

Effect of HMPH on NO production and iNOS protein expression levels in LPS-activated RAW264.7 macrophages. The present study further explored the inhibitory activity of $\mathrm{HMPH}$ on NO in LPS-activated RAW264.7 macrophages. The inhibitory effect of HMPH on NO in LPS-activated RAW264.7 cells was assessed by Griess assay. The results revealed that LPS significantly induced NO production compared with in the control cells (without LPS treatment) (Fig. 2A). Pretreatment with $\mathrm{HMPH}$, at concentrations ranging between 0.63 and $20 \mu \mathrm{M}$, significantly inhibited LPS-induced NO secretion in a dose-dependent manner, whereas curcumin suppressed NO production at higher concentrations of 1.25-20 $\mu \mathrm{M}$ (Fig. 2A). These findings indicated that HMPH was more effective than curcumin at inhibiting NO production. The suppression of iNOS protein expression levels by HMPH were further 
A

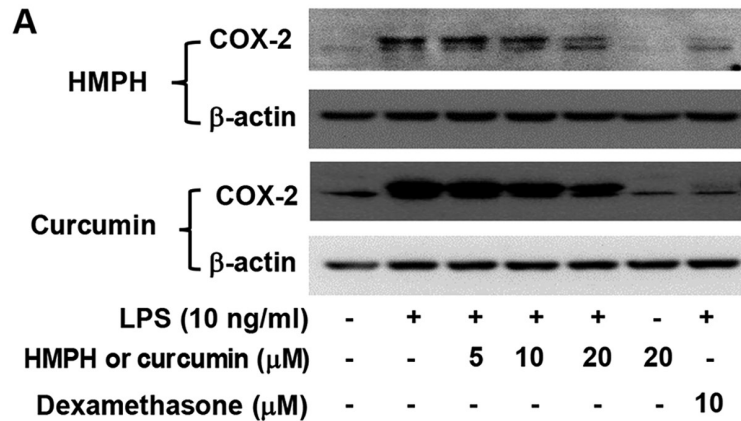

B
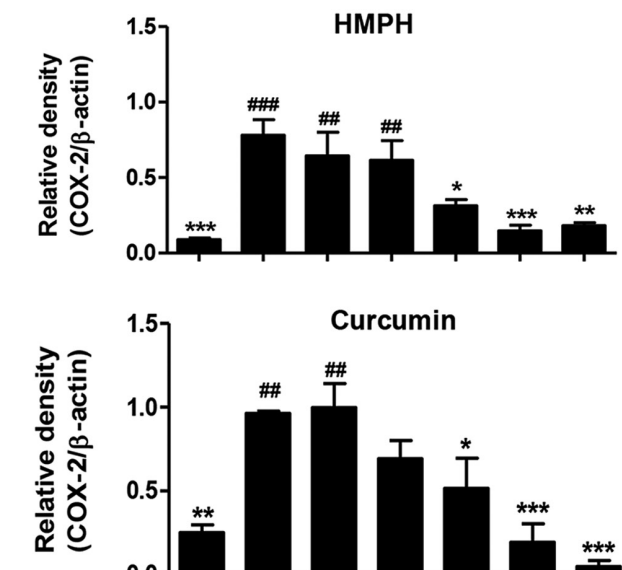

LPS $(10 \mathrm{ng} / \mathrm{ml})$.

HMPH or curcumin $(\mu \mathrm{M})$ -

Dexamethasone $(\mu \mathrm{M})$ -

Figure 3. HMPH suppresses COX-2 expression in LPS-activated RAW264.7 macrophages. (A) Protein expression levels of COX-2 were determined by western blotting. For HMPH treatment group, the representative images of COX-2 (exposure time: $20 \mathrm{~min}$ ) and $\beta$-actin (exposure time: $1 \mathrm{~min}$ ) were from two different parts of the same blotted membranes. For the curcumin treatment group, the two representative images of COX-2 (exposure time: $1.20 \mathrm{~min}$ ) and $\beta$-actin (exposure time: $1 \mathrm{~min}$ ) were taken from different membranes. The COX-2 blotting image from the curcumin treatment group was acquired using a different imaging system. (B) Relative expression levels of COX-2 were semi-quantified by scanning densitometry and normalized to $\beta$-actin. Data are presented as the mean \pm SEM of three independent experiments. ${ }^{\# \#} \mathrm{P}<0.01$,

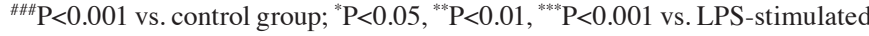
group. HMPH, 1,7-bis(4-hydroxy-3-methoxyphenyl)-1,4,6-heptatrien-3-one; LPS, lipopolysaccharide; COX-2, cyclooxygenase 2.

investigated in LPS-activated RAW264.7 cells. Upon LPS stimulation, the protein expression levels of iNOS were significantly increased (Fig. 2B and C). Pretreatment with 5-20 $\mu \mathrm{M} \mathrm{HMPH}$ and curcumin significantly decreased the protein expression levels of iNOS in LPS-activated macrophages compared with LPS treatment alone. The anti-inflammatory drugs dexamethasone and BAY 11-7082 also significantly inhibited NO production and iNOS protein expression compared with LPS-treated cells.

Effect of HMPH on COX-2 protein expression levels in LPS-activated RAW264.7 macrophages. As curcumin has been shown to inhibit COX-2 protein expression (20), the present study investigated the inhibition of COX-2 expression by HMPH. HMPH at $20 \mu \mathrm{M}$ (Fig. $3 \mathrm{~A}$ and B) significantly inhibited the protein expression levels of COX-2 in LPS-activated RAW264.7 macrophages; curcumin exhibited a similar effect at the same concentration. Compared with HMPH and
A

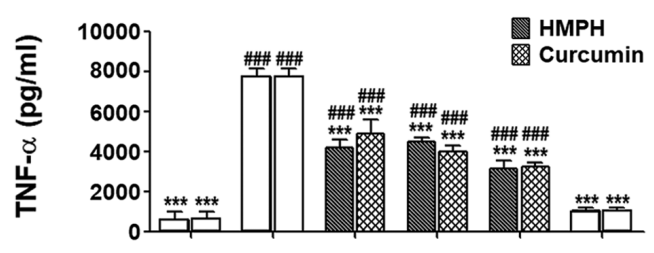

B

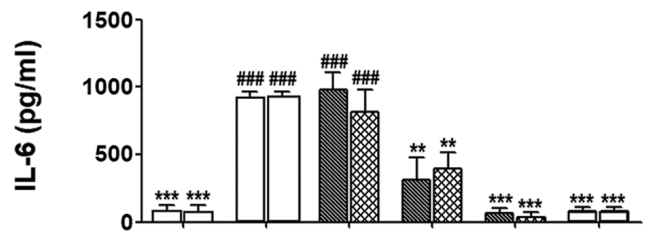

C

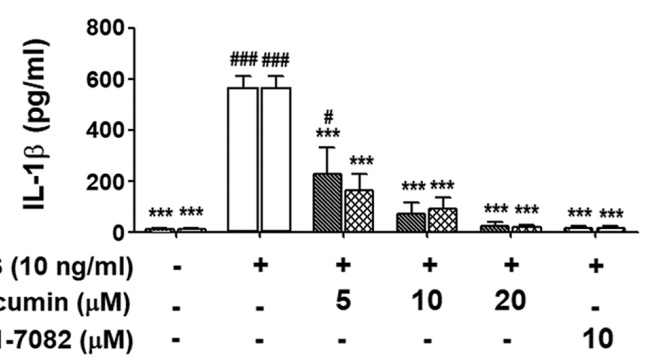

Figure 4. Inhibitory effect of HMPH on the production of inflammatory cytokines in LPS-activated RAW264.7 cells. Cells were pretreated with different concentrations $(5-20 \mu \mathrm{M})$ of HMPH and curcumin for $1 \mathrm{~h}$ and then treated with LPS for $24 \mathrm{~h}$. (A) TNF- $\alpha$, (B) IL-6, and (C) IL-1 $\beta$ levels in the culture media were detected using ELISA kits. Data are presented as the mean \pm SEM of three independent experiments. ${ }^{\# P}<0.05,{ }^{\# \# \#} \mathrm{P}<0.001$ vs. control group; ${ }^{* *} \mathrm{P}<0.01,{ }^{* * *} \mathrm{P}<0.001$ vs. LPS-stimulated group. HMPH, 1,7-bis(4hydroxy-3-methoxyphenyl)-1,4,6-heptatrien-3-one; LPS, lipopolysaccharide.

curcumin, dexamethasone possessed a stronger inhibitory effect on COX-2 protein expression (Fig. 3).

Effect of HMPH on inflammatory cytokine production in LPS-activated RAW264.7 macrophages. The present study also investigated the suppression of cytokine production in LPS-activated macrophages using ELISA. Upon stimulation with LPS for $24 \mathrm{~h}$, the production of TNF- $\alpha$ (Fig. 4A), IL-6 (Fig. 4B) and IL-1 $\beta$ (Fig. 4C) was significantly increased. Pretreatment of cells with $\mathrm{HMPH}$ at $10-20 \mu \mathrm{M}$ markedly inhibited LPS-induced TNF- $\alpha$, IL- 6 and IL-1 $\beta$ production (Fig. 4A-C). Curcumin exhibited a similar trend with regards to suppression of these inflammatory cytokines. BAY 11-7082 $(10 \mu \mathrm{M})$ also significantly inhibited the production of all inflammatory cytokines measured.

Effect of HMPH on LPS-activated NF- $\kappa B$ translocation in RAW264.7 macrophages. NF- $\mathrm{KB}$ is an important signalling protein involved in the activation of inflammation $(7,8)$. The present study further investigated the effect of HMPH on the suppression of p65 NF- $\kappa \mathrm{B}$ nuclear translocation. Upon LPS stimulation, p65 NF- $\kappa \mathrm{B}$ translocated into the nucleus (Fig. 5). HMPH (10-20 $\mu \mathrm{M})$ significantly suppressed 065 NF- $\kappa B$ translocation into the nucleus; however, HMPH had no effect on p65 NF- $\kappa B$ expression in the cytoplasm (Fig. 5A). The mechanism of action of HMPH on the suppression of p65 NF- $\kappa B$ translocation was greater than that of curcumin (Fig. 5B). BAY 11-7082 $(10 \mu \mathrm{M})$ also significantly suppressed the 
A
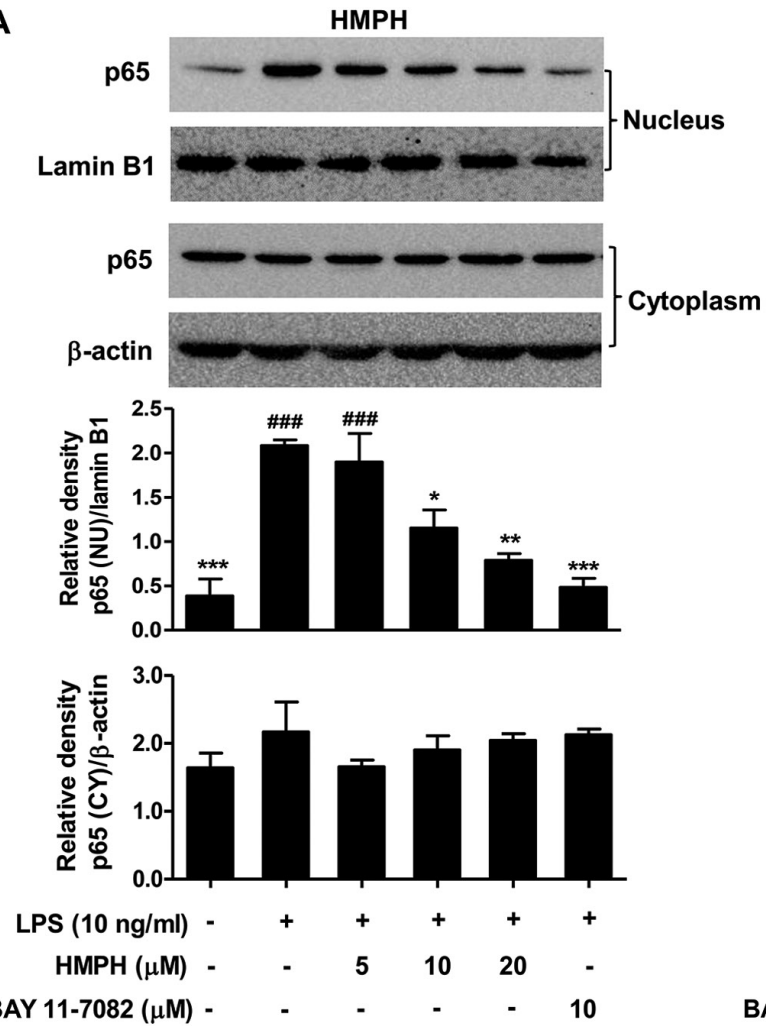

B
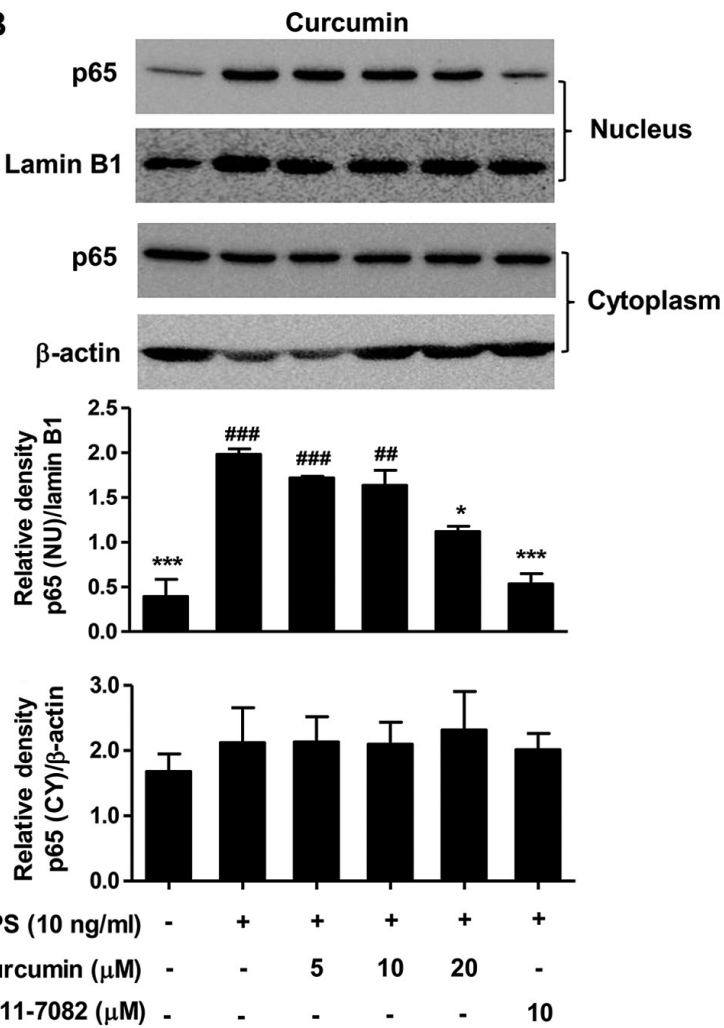

Figure 5. HMPH suppresses LPS-activated p65 NF- $\mathrm{kB}$ translocation in RAW264.7 macrophages. Proteins were prepared from RAW264.7 cells pretreated with or without different concentrations $(5-20 \mu \mathrm{M})$ of (A) HMPH and (B) curcumin for $1 \mathrm{~h}$ followed by LPS treatment (10 ng/ml) for $15 \mathrm{~min}$. The protein expression levels of p65 NF- $\kappa \mathrm{B}$ were determined by western blotting (top panel) and relative expression levels were normalized to $\beta$-actin or lamin B1 (bottom panel). For the NU fraction, the two representative images of $\mathrm{p} 65 \mathrm{NF}-\kappa \mathrm{B}$ and lamin B1 were taken from different blotted membranes. For the $\mathrm{CY}$ fraction, the two representative images of p65 NF- $\kappa \mathrm{B}$ and $\beta$-actin were from the same membrane. Data are presented as the mean \pm SEM of three independent experiments. ${ }^{\#} \mathrm{P}<0.01$

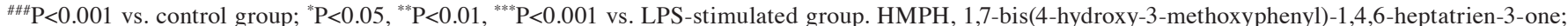

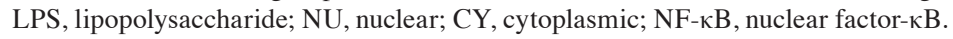

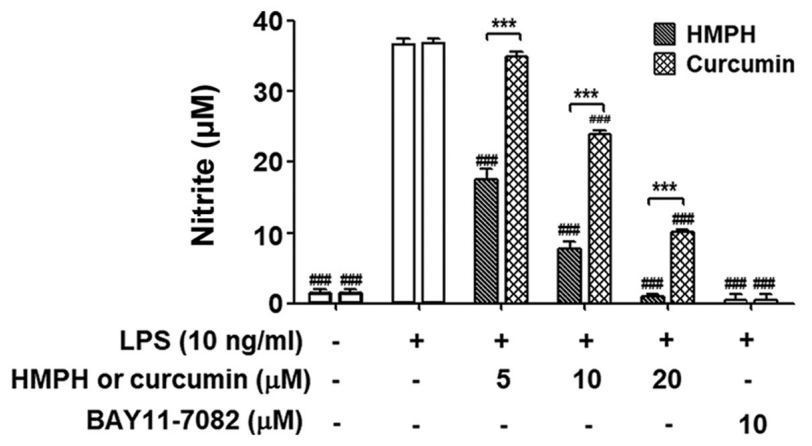

Figure 6. Effect of HMPH on cells. RAW264.7 cells were pretreated with different concentrations $(5-20 \mu \mathrm{M})$ of HMPH and curcumin for $1 \mathrm{~h}$, washed three times and then stimulated with LPS (10 ng/ml). After $24 \mathrm{~h}$, nitrite from the culture supernatant was measured by Griess assay. Data are presented as the mean \pm SEM of three independent experiments. ${ }^{\# \#} \mathrm{P}<0.001$ vs. LPS-stimulated group; ${ }^{* * *} \mathrm{P}<0.001$ vs. curcumin-treated group. HMPH, 1,7-bis(4-hydroxy-3-m ethoxyphenyl)-1,4,6-heptatrien-3-one; LPS, lipopolysaccharide.

translocation of p65 NF- $\kappa \mathrm{B}$ into the nucleus. These findings are consistent with the results obtained from immunofluorescence staining of p65 NF- $\kappa \mathrm{B}$ in RAW264.7 cells treated with LPS for 15 min (Fig. S4) and 30 min (Fig. S5). After treatment with $\mathrm{HMPH}$, p65 NF-кB protein expression, as indicated by green fluorescence, was retained mainly in the cytoplasm of LPS-activated macrophages, similar to that observed in cells treated with BAY 11-7082 (Figs. S4 and S5). Cells pretreated with curcumin exhibited both nuclear and cytoplasmic localisation of NF- $\mathrm{NB}$ following LPS stimulation, indicating a less pronounced effect than that observed in response to HMPH.

Effect of pretreatment with HMPH on LPS stimulation in RAW264.7 macrophages. To investigate whether the anti-inflammatory effect of HMPH on the LPS-induced inflammatory response was due to its effect on the cells, RAW264.7 cells were pretreated with HMPH for $1 \mathrm{~h}$ and were then thoroughly washed to remove HMPH before LPS stimulation for 24 h. Curcumin was used for comparison with HMPH treatment. Notably, inhibition of NO production was still observed after the removal of HMPH (5-20 $\mu \mathrm{M})$ and curcumin $(10-20 \mu \mathrm{M})$ prior to LPS stimulation (Fig. 6). BAY 11-7082 (10 $\mu \mathrm{M})$ completely inhibited NO production after the washout, this finding was similar to that observed in cells treated with $20 \mu \mathrm{M}$ HMPH. These data suggested that HMPH may act on cells and exert anti-inflammatory action prior to LPS stimulation.

Effect of HMPH on MD2. Previous results demonstrated that HMPH could inhibit inflammatory responses in activated macrophages and the inhibition of LPS-induced inflammation may be through the complex formation of $\mathrm{HMPH}$ with MD2 $(10,21)$. The binding of HMPH to the MD2 protein pocket was subsequently assessed and compared with the binding of curcumin. Molecular docking was applied to predict the possible interaction between HMPH and the MD2 protein 
Table I. Summary of the binding interactions and energies of MD2-HMPH and MD2-curcumin complexes.

\begin{tabular}{lllccc}
\hline Compound & \multicolumn{1}{c}{ Interaction } & \multicolumn{1}{c}{ Residue } & Distance $(\AA)$ & $\Delta \mathrm{G}_{\text {docking }}(\mathrm{kcal} / \mathrm{mol})$ & $\Delta \mathrm{G}_{\mathrm{MM} / \mathrm{PBSA}}(\mathrm{kcal} / \mathrm{mol})$ \\
\hline HMPH & Hydrogen bond & R90, C133 & $2.28 / 2.42,2.08$ & -6.12 & -29.56 \\
& Pi-Sigma & F151 & 3.87 & \\
\multirow{2}{*}{ Curcumin } & Pi-Alkyl & I80, L87, V135 & $5.32,5.41,4.58$ & -5.64 & -25.63 \\
& Hydrogen bond & R90 & 1.81 & & \\
& Pi-Pi & Y131, F151 & $4.97,3.98$ & 3.42 & \\
& Pi-Sigma & I124 & 4.59 & & \\
& Pi-Alkyl & I80 & & \\
\hline
\end{tabular}

HMPH, 1,7-bis(4-hydroxy-3-methoxyphenyl)-1,4,6-heptatrien-3-one; MD2, myeloid differentiation factor 2.

A

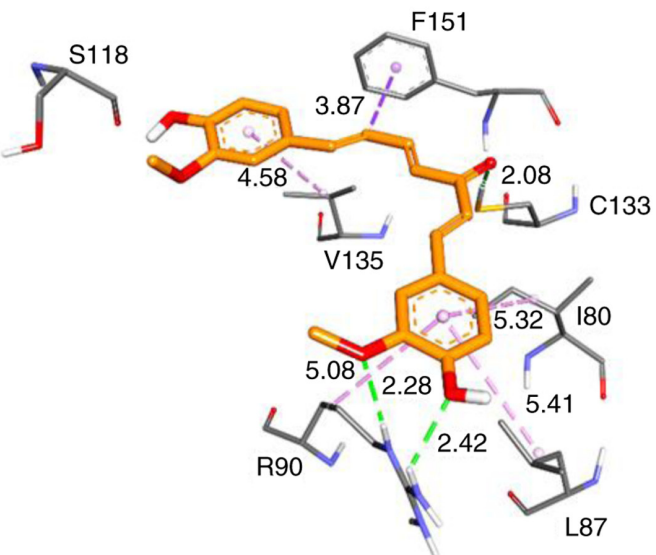

B

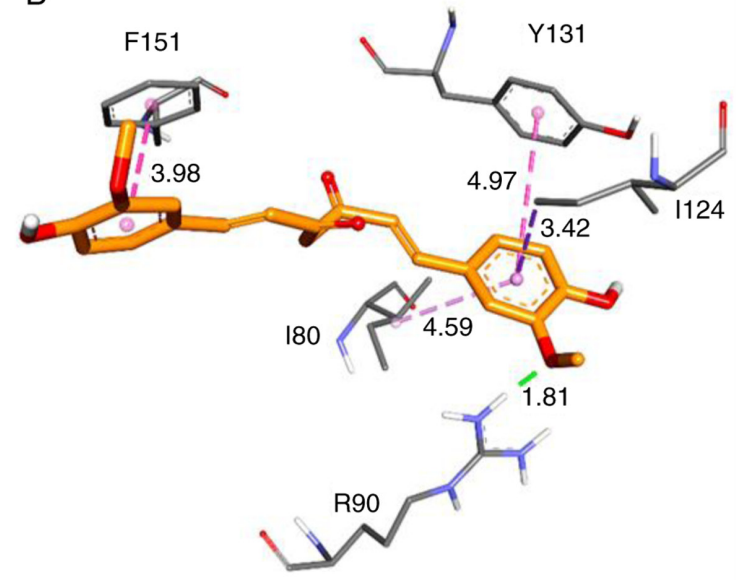

Figure 7. HMPH interacts with MD2, as determined by in silico analysis. Analysis of interactions between myeloid differentiation factor 2 and (A) HMPH and (B) curcumin. HMPH, 1,7-bis(4-hydroxy-3-methoxyphenyl)1,4,6-heptatrien-3-one.

using AutoDock4.2. The lowest binding energy represents the best binding conformation between the protein and ligand. Table I summarises the results of the docking study based on binding interactions and energies. The minimised structures of the best conformation of MD2-HMPH and MD2-curcumin docked complexes are shown in Fig. 7. The results revealed that HMPH can form a stronger interaction with MD2 protein than curcumin. There are two hydrogen bond interactions involving amino acids R90 and C133, as well as the hydrophobic interactions with the residues F151, I80, L87 and V135 that were observed in the MD2-HMPH complex (Fig. 7A). Conversely, curcumin interacted with MD2 by forming a hydrogen bond with R90, as well as forming hydrophobic interactions with Y131, F151, I124 and I80 residues of the MD2 protein (Fig. 7B).

MM/PBSA binding free energy of MD2-HMPH complex. The present study further calculated the binding free energy of MD2-HMPH compared with MD2-curcumin complexes using a more reliable method, MM/PBSA. As shown in Table I, $\mathrm{HMPH}\left(\Delta \mathrm{G}_{\mathrm{MM} / \mathrm{PBSA}},-29.56 \mathrm{kcal} / \mathrm{mol}\right)$ had a more energetically favourable value in the MD2 binding pocket than curcumin $\left(\Delta \mathrm{G}_{\mathrm{MM} / \mathrm{PBSA}},-25.63 \mathrm{kcal} / \mathrm{mol}\right)$, which indicated strong binding between MD2 and HMPH compared with the MD2-curcumin complex. These results indicated that the effect of HMPH on the inflammatory response in macrophages may be achieved through interfering with MD2 protein.

\section{Discussion}

Numerous stable curcuminoid analogues have been isolated and synthesised to investigate their potential biological functions $(23,29)$. The present study explored the anti-inflammatory activity and the underlying molecular effect of HMPH on LPS-activated RAW264.7 macrophages. To the best of our knowledge, the present study was the first to reveal that HMPH exhibited superior suppression of inflammatory mediators compared with curcumin and its action was associated with the suppression of $\mathrm{NF}-\kappa \mathrm{B}$ translocation. Furthermore, the inhibitory effect of HMPH on the inflammatory response may be achieved through interfering with MD2 binding, thereby interrupting the inflammatory cascade. In previous studies, modification of the easily decomposed $\alpha, \beta$-unsaturated $\beta$-diketo moiety of curcumin could enhance the stability and anti-inflammatory effect of curcuminoid analogues $(23,30)$, and thus, this may be the reason why HMPH containing unsaturated trienone linker possessed superior anti-inflammatory effects than curcumin.

Upon inflammation, LPS forms a complex with plasma LPS-binding protein, which leads to the transfer of the complexes to CD14 located at the cell membrane of macrophages (3). CD14 transfers LPS to the receptor complex, which consists of TLR4 and MD2, leading to induction of myeloid differentiation 88-dependent and TIR-domain-containing adapter-inducing interferon- $\beta$-dependent signalling, thereby directly activating the downstream signalling proteins of the $N F-\kappa B$ pathway (31). 
The anti-inflammatory action of curcumin in macrophages has also been shown to be due to interfering with LPS binding to the TLR4/MD2 complex and blocking of signalling molecules in the inflammatory pathway (21). It has been reported that curcumin may form hydrogen bonds with residues R90 and Y102 of the MD2 protein, and the binding affinity of these two interactions was decreased in the MD2R90A/Y102A mutant system (32). In silico modelling revealed that HMPH formed a stronger interaction with the MD2 protein than curcumin. The present results are consistent with those of previous reports, which reported that the amino acids R90, Y102 and C133 were possible key residues in the interaction between the MD2 protein and small molecules, such as curcumin and synthetic chalcone L6H21 $(21,32,33)$. The three curcuminoid analogues L48H37, MAC17 and MAC28 have been shown to attenuate the LPS-induced TLR4/MD2-downstream proinflammatory $\mathrm{NF}-\kappa \mathrm{B}$ signalling pathway possibly through binding with the R90 residue of the MD2 protein (10,34). It was suggested that inhibition of MD2 by curcuminoid analogues at the possible key residues may interfere with the upstream components of the $\mathrm{NF}-\kappa \mathrm{B}$ signalling pathway, thus leading to the attenuation of inflammation. However, further research is required to confirm these findings.

Macrophages secrete large amounts of pro-inflammatory mediators that can be harmful and result in a deleterious effect during the inflammatory response (1). A previous study demonstrated that curcumin markedly reduced inflammation via suppression of iNOS/NO, COX-2, and the inflammatory cytokines IL-1 $\beta$, IL- 6 and TNF- $\alpha$ in LPS-activated RAW264.7 cells by targeting multiple signalling pathways $(19,20,35)$. It has also been reported that the mechanism of action of curcumin may involve modulation of the $\mathrm{NF}-\kappa \mathrm{B}$ signalling pathway $(20,36)$. Furthermore, curcumin has been reported to inhibit LPS-induced I $\mathrm{B} \alpha$ degradation, with concomitant inhibition of p65 and p50 nuclear translocation in RAW264.7 cells (37). Similar to these findings with curcumin, the present study demonstrated that HMPH could significantly inhibit iNOS/NO, COX-2 and inflammatory cytokine production via suppression of p65 NF- $\kappa$ B translocation into the nucleus in a model of LPS-activated RAW264.7 cells. This evidence may support the potential use of HMPH to attenuate macrophage inflammatory activities.

The present study had some limitations. Typically, the translocation of $\mathrm{NF}-\kappa \mathrm{B}$ into the nucleus after activation is consistently related to its functions as a transcription factor. In a previous study, the inhibition of nuclear p65 NF- $\kappa \mathrm{B}$ translocation by mycoepoxydiene in LPS-activated RAW264.7 cells was concomitant with the suppression of NF- $\kappa$ B DNA binding and transcriptional activities, which consequently attenuated the inflammatory response (38). However, the lack of electromobility shift assay (EMSA) detection was a limitation of the present study. To further support the present findings, the inhibition of nuclear NF- $\kappa \mathrm{B}$ translocation by HMPH should be conducted in parallel with EMSA detection to provide a better explanation of the function of NF- $\kappa \mathrm{B}$ in the transcriptional regulation of target genes involved in the inflammatory response. In addition, there are some challenges in assessing the interaction of HMPH with MD2. The present study demonstrated a strong binding between HMPH and MD2 using an in silico study; however, to the best of our knowledge, there have been no reports on the complex formation of HMPH with MD2, and its effects on the suppression of $\mathrm{NF}-\kappa \mathrm{B}$ activation and inflammation. It would be interesting to conduct further experiments based on the binding affinity of HMPH with MD2 or mutant MD2, and the subsequent effects on the inhibition of NF- $\kappa \mathrm{B}$ activation and inflammation.

In conclusion, HMPH possessed greater anti-inflammatory activity than curcumin via suppression of inflammatory mediators in LPS-activated RAW264.7 macrophages. The present finding provided an insight into the molecular mechanism by which HMPH attenuates inflammation through the suppression of iNOS/NO, COX-2, inflammatory cytokines and NF- $\kappa \mathrm{B}$ translocation. In silico modelling demonstrated that HMPH formed two stable hydrogen bonds with the key residues R90 and $\mathrm{C} 133$ of the MD2 protein, and thus, may block inflammatory signalling pathways. These findings indicated that HMPH may exert potential anti-inflammatory effects and may be considered a promising novel therapeutic agent for the treatment of inflammatory diseases.

\section{Acknowledgements}

Not applicable.

\section{Funding}

This work was supported by the Walailak University Fund (grant nos. WU61201, 020101/02/2559 and 09/2561), The Royal Golden Jubilee Ph.D. Program (grant no. RGJ PHD/0216/2561), The Thailand Research Fund (grant no. DBG6180030) and the Center of Excellence for Innovation in Chemistry (PERCH-CIC).

\section{Availability of data and materials}

The datasets used and/or analysed during the current study are available from the corresponding author on reasonable request.

\section{Authors' contributions}

CJ, WanC, WaralC, PY and KL performed experiments, analysed data and reviewed the manuscript. WiC, ASa, PH, KK and TU participated in study design and supervised the study. $\mathrm{ASu}$ and WaranC aided in the experimental design, refined the manuscript, and corresponded during the manuscript submission and revision. All authors read and approved the final manuscript.

\section{Ethics approval and consent to participate}

Not applicable.

\section{Patient consent for publication}

Not applicable.

\section{Competing interests}

The authors declare that they have no competing interests 


\section{References}

1. Karakike E, Adami ME,Lada M, Gkavogianni T, Koutelidakis IM, Bauer M, Giamarellos-Bourboulis EJ and Tsangaris I: Late peaks of HMGB1 and sepsis outcome evidence for synergy with chronic inflammatory disorders. Shock 52: 334-339, 2019.

2. Stengel S, Quickert S, Lutz P, Ibidapo-Obe O, Steube A Köse-Vogel N, Yarbakht M, Reuken PA, Busch M, Brandt A, et al: Peritoneal level of CD206 associates with mortality and an inflammatory macrophage phenotype in patients with decompensated cirrhosis and spontaneous bacterial peritonitis. Gastroenterology 158: 1745-1761,2020.

3. Rajaiah R, Perkins DJ, Ireland DD and Vogel SN: CD14 dependence of TLR4 endocytosis and TRIF signaling displays ligand specificity and is dissociable in endotoxin tolerance. Proc Natl Acad Sci USA 112: 8391-8396, 2015.

4. Chen L, Deng H, Cui H, Fang J, Zuo Z, Deng J, Li Y, Wang X and Zhao L: Inflammatory responses and inflammation-associated diseases in organs. Oncotarget 9: 7204-7218, 2017.

5. Pizzuto M, Lonez C, Baroja-Mazo A, Martínez-Banaclocha $\mathrm{H}$, Tourlomousis P, Gangloff M, Pelegrin P, Ruysschaert JM, Gay NJ and Bryant CE: Saturation of acyl chains converts cardiolipin from an antagonist to an activator of Toll-like receptor-4. Cell Mol Life Sci 76: 3667-3678, 2019.

6. Taniguchi $\mathrm{K}$ and Karin M: NF- $\mathrm{BB}$, inflammation, immunity and cancer: Coming of age. Nat Rev Immunol 18: 309-324, 2018

7. Obaid M, Udden SMN, Deb P, Shihabeddin N, Zaki MH and Mandal SS: LncRNA HOTAIR regulates lipopolysaccharide-induced cytokine expression and inflammatory response in macrophages. Sci Rep 8: 15670, 2018.

8. Aoki T, Frồsen J, Fukuda M, Bando K, Shioi G, Tsuji K, Ollikainen E, Nozaki K, Laakkonen J and Narumiya S: Prostaglandin E2-EP2-NF- $\mathrm{B}$ signaling in macrophages as a potential therapeutic target for intracranial aneurysms. Sci Signal 10: eaah6037, 2017.

9. Manček-Keber M, Gradišar H, Iñigo Pestaña M, Martinez de Tejada G and Jerala R: Free thiol group of MD-2 as the target for inhibition of the lipopolysaccharide-induced cell activation. J Biol Chem 284: 19493-19500, 2009.

10. Wang Y, Shan X, Dai Y, Jiang L, Chen G, Zhang Y, Wang Z, Dong L, Wu J, Guo G, et al: Curcumin analog L48H37 prevents lipopolysaccharide-induced TLR4 signaling pathway activation and sepsis via targeting MD2. J Pharmacol Exp Ther 353: 539-550, 2015.

11. Kocaadam B and Şanlier N: Curcumin, an active component of turmeric (Curcuma longa), and its effects on health. Crit Rev Food Sci Nutr 57: 2889-2895, 2017.

12. Akter J, Hossain MA, Takara K, Islam MZ and Hou DX: Antioxidant activity of different species and varieties of turmeric (Curcuma spp): Isolation of active compounds. Comp Biochem Physiol C Toxicol Pharmacol 215: 9-17, 2019.

13. Park SY and Kim DS: Discovery of natural products from Curcuma longa that protect cells from beta-amyloid insult: A drug discovery effort against Alzheimer's disease. J Nat Prod 65: 1227-1231, 2002.

14. Chuprajob T, Changtam C, Chokchaisiri R, Chunglok W, Sornkaew N and Suksamrarn A: Synthesis, cytotoxicity against human oral cancer KB cells and structure-activity relationship studies of trienone analogues of curcuminoids. Bioorg Med Chem Lett 24: 2839-2844, 2014.

15. Wang R, Zhang X, Chen C, Chen G, Zhong Q, Zhang Q, Zheng S, Wang $G$ and Chen QH: Synthesis and evaluation of 1,7-diheteroarylhepta-1,4,6-trien-3-ones as curcumin-based anticancer agents. Eur J Med Chem 110: 164-180, 2016.

16. Utaipan T, Boonyanuphong P, Chuprajob T, Suksamrarn A and Chunglok W: A trienone analog of curcumin, 1,7-bis (3-hydroxyphenyl)-1,4,6-heptatrien-3-one, possesses ROS- and caspase-mediated apoptosis in human oral squamous cell carcinoma cells in vitro. Appl Biol Chem 63: 7, 2020.

17. Srivilai J, Rabgay K, Khorana N, Waranuch N, Nuengchamnong N, Wisuitiprot W, Chuprajob T, Changtam C, Suksamrarn A, Chavasiri W, et al: Anti-androgenic curcumin analogues as steroid 5-alpha reductase inhibitors. Med Chem Res 26 : 1550-1556, 2017.

18. Jang MK, Sohn DH and Ryu JH: A curcuminoid and sesquiterpenes as inhibitors of macrophage TNF- $\alpha$ release from Curcuma zedoaria. Planta Med 67: 550-552, 2001.

19. Tan RZ, Liu J, Zhang YY, Wang HL, Li JC, Liu YH, Zhong X, Zhang YW, Yan Y, Lan HY, et al: Curcumin relieved cisplatin-induced kidney inflammation through inhibiting Mincle-maintained M1 macrophage phenotype. Phytomedicine 52: 284-294, 2019.
20. Zhao F, Gong Y, Hu Y, Lu M, Wang J, Dong J, Chen D, Chen L, Fu F and Qiu F: Curcumin and its major metabolites inhibit the inflammatory response induced by lipopolysaccharide: Translocation of nuclear factor- $\kappa \mathrm{B}$ as potential target. Mol Med Rep 11: 3087-3093, 2015.

21. Gradišar H, Keber MM, Pristovšek P and Jerala R: MD-2 as the target of curcumin in the inhibition of response to LPS. J Leukoc Biol 82: 968-974, 2007.

22. Mirzaei H, Shakeri A, Rashidi B, Jalili A, Banikazemi Z and Sahebkar A: Phytosomal curcumin: A review of pharmacokinetic, experimental and clinical studies. Biomed Pharmacother 85: 102-112, 2017.

23. Koeberle A, Muñoz E, Appendino GB, Minassi A, Pace S, Rossi A, Weinigel C, Barz D, Sautebin L, Caprioglio D, et al: SAR studies on curcumin's pro-inflammatory targets: Discovery of prenylated pyrazolocurcuminoids as potent and selective novel inhibitors of 5-lipoxygenase. J Med Chem 57: 5638-5648, 2014.

24. Changtam C, de Koning HP, Ibrahim H, Sajid MS, Gould MK and Suksamrarn A: Curcuminoid analogs with potent activity against Trypanosoma and Leishmania species. Eur J Med Chem 45: 941-956, 2010.

25. Sun J, Zhang X, Broderick M and Fein H: Measurement of nitric oxide production in biological systems by using Griess reaction assay. Sensors (Basel) 3: 276-284, 2003.

26. Morris GM, Huey R, Lindstrom W, Sanner MF, Belew RK, Goodsell DS and Olson AJ: AutoDock4 and AutoDockTools4: Automated docking with selective receptor flexibility. J Comput Chem 30: 2785-2791, 2009.

27. Morris G, Goodsell D, Halliday R, Huey R, Hart W, Belew R and Olson A: Automated docking using a lamarckian genetic algorithm and an empirical binding free energy function. J Comput Chem 19: 1639-1662, 1998.

28. Case DA, Betz RM, Cerutti DS, Cheatham TE, Darden TA, Duke RE, Giese TJ, Gohlke H, Goetz AW, Homeyer N, et al: AMBER 2016. University of California, San Francisco, 2016

29. Liang G, Li X, Chen L, Yang S, Wu X, Studer E, Gurley E, Hylemon PB, Ye F, Li Y, et al: Synthesis and anti-inflammatory activities of mono-carbonyl analogues of curcumin. Bioorg Med Chem Lett 18: 1525-1529, 2008.

30. Zhao C, Zhang Y, Zou P, Wang J, He W, Shi D, Li H, Liang G and Yang S: Synthesis and biological evaluation of a novel class of curcumin analogs as anti-inflammatory agents for prevention and treatment of sepsis in mouse model. Drug Des Devel Ther 9: 1663-1678, 2015

31. Ullah MO, Sweet MJ, Mansell A, Kellie S and Kobe B: TRIF-dependent TLR signaling, its functions in host defense and inflammation, and its potential as a therapeutic target. J Leukoc Biol 100: 27-45, 2016.

32. Wang Z, Chen G, Chen L, Liu X, Fu W, Zhang Y, Li C, Liang G and Cai Y: Insights into the binding mode of curcumin to MD-2: Studies from molecular docking, molecular dynamics simulations and experimental assessments. Mol Biosyst 11: 1933-1938, 2015.

33. Wang Y, Shan X, Chen G, Jiang L, Wang Z, Fang Q, Liu X, Wang J, Zhang Y, Wu W, et al: MD-2 as the target of a novel small molecule, L6H21, in the attenuation of LPS-induced inflammatory response and sepsis. Br J Pharmacol 172: 4391-4405, 2015.

34. Zhang Y, Liu Z, Wu J, Bai B, Chen H, Xiao Z, Chen L, Zhao Y, Lum H, Wang Y, et al: New MD2 inhibitors derived from curcumin with improved anti-inflammatory activity. Eur J Med Chem 148: 291-305, 2018.

35. Li B, Hu Y, Zhao Y, Cheng M, Qin H, Cheng T, Wang Q, Peng X and Zhang X: Curcumin attenuates titanium particle-induced inflammation by regulating macrophage polarization in vitro and in vivo. Front Immunol 8: 55, 2017

36. Zhang J, Zheng Y, Luo Y, Du Y, Zhang X and Fu J: Curcumin inhibits LPS-induced neuroinflammation by promoting microglial M2 polarization via TREM2/TLR4/NF- $\kappa \mathrm{B}$ pathways in BV2 cells. Mol Immunol 116: 29-37, 2019.

37. Oh SW, Cha JY, Jung JE, Chang BC, Kwon HJ, Lee BR and Kim DY: Curcumin attenuates allergic airway inflammation and hyper-responsiveness in mice through $\mathrm{NF}-\kappa \mathrm{B}$ inhibition. J Ethnopharmacol 136: 414-421, 2011

38. Chen Q, Chen T, Li W, Zhang W, Zhu J, Li Y, Huang Y, Shen Y and Yu C: Mycoepoxydiene inhibits lipopolysaccharide-induced inflammatory responses through the of TRAF6 polyubiquitination. PLoS One 7: e44890, 2012. 